\title{
Visual experience during phacoemulsification cataract surgery under topical anaesthesia
}

\author{
Douglas K Newman
}

\begin{abstract}
Backgroundlaims-Visual awareness during phacoemulsification cataract surgery is an important determinant of patient satisfaction with any anaesthetic technique. Topical anaesthesia could be associated with significant visual awareness because it does not affect optic nerve function.

Methods-The visual experience during phacoemulsification cataract surgery under topical anaesthesia (without sedation) was assessed for 106 consecutive unselected patients. Patients were interviewed immediately after surgery using a standardised questionnaire that explored specific aspects of their visual experience. Results-Four patients were excluded because they had poor recollection of their visual experience. The visual awareness of the remaining 102 patients comprised operating microscope light (99), colours (73), flashes of light (7), vague movements (19), surgical instruments or other objects (12), change in light brightness during surgery (49), change in colours during surgery (30), and transient visual alteration during corneal irrigation (25). No patient found their visual experience during surgery unpleasant, though the operating microscope light was uncomfortably bright for two patients. Six patients lost light perception for a short interval during surgery. There was no association between the various visual phenomena reported and patients' age, sex, preoperative visual acuity, cataract morphology, coexisting ocular pathology, or previous experience of cataract surgery under local anaesthesia $(p>0.05)$.
\end{abstract}

Conclusions-Patients experience a wide variety of visual sensations during phacoemulsification cataract surgery under topical anaesthesia. Topical anaesthesia does not, however, appear to result in greater visual awareness than regional anaesthesia. Preoperative patient counselling should include information about the visual experience during surgery.

(BrF Ophthalmol 2000;84:13-15)

Ophartment of Norwich Hospital, Bowthorpe Road, Norwich NR2 3TU D K Newman

Correspondence to: Department of

Ophthalmology, Clinic 3

(Box 41), Addenbrooke's

Hospital, Hills Road,

Cambridge CB2 2QQ

Accepted for publication 25 August 1999

Phacoemulsification cataract surgery is increasingly being performed under topical anaesthesia. Several studies have demonstrated that it provides satisfactory analgesia, comparable with regional blocks (retrobulbar, peribulbar, and sub-Tenon's anaesthesia). ${ }^{1-11}$ However, the visual experience of patients during phacoemulsification cataract surgery under topical anaesthesia has not been assessed. Since optic nerve function is not affected by topical anaesthesia, patients may have greater visual awareness dur- ing surgery with this method of anaesthesia compared with regional blocks. ${ }^{12-14}$ Visual awareness during surgery is an important determinant of patient satisfaction with any anaesthetic technique for phacoemulsification cataract surgery.

\section{Patients and methods}

The visual experience of 106 consecutive patients during phacoemulsification cataract surgery under topical anaesthesia was assessed. Patients were not preselected for topical anaesthesia since this was the surgeon's standard anaesthetic technique for cataract surgery during the period of this study.

Anaesthesia was achieved with amethocaine $1 \%$ (four drops) instilled over a 30 minute interval preoperatively and prilocaine $2 \%(0.2$ $\mathrm{ml}$ ) injected subconjunctivally at the incision site immediately before surgery. Patients did not receive perioperative sedation or any other medication that might impair cognitive function. Surgery was performed by a single surgeon using a self sealing scleral tunnel incision, continuous curvilinear capsulorhexis, bimanual nucleofractis phacoemulsification, automated aspiration of cortical remnants, and insertion of a $5.0 \mathrm{~mm}$ poly(methylmethacrylate) intraocular lens into the capsular bag. The operating microscope employed coaxial illumination with two light sources (Zeiss illumination system).

Patients were interviewed within 30 minutes of the completion of surgery using a standardised questionnaire. The questionnaire explored specific aspects of their visual experience: (1) operating microscope light (brightness and form); (2) colours; (3) flashes of light; (4) awareness of movement; (5) perception of surgical instruments or other objects; (6) change in light brightness during surgery; (7) change in colours during surgery; (8) effect of corneal irrigation; and (9) overall acceptability of visual experience. Patients were then invited to describe any additional aspects of their visual experience that had not been covered by the questionnaire.

\section{Results}

The visual experience during phacoemulsification cataract surgery was analysed for 102 patients. Four patients were excluded because they had poor recollection of their visual experience because of dementia. The median age of the patients was 79 years (range 55-98 years), with 36 males and 66 females. There were 46 right eyes and 56 left eyes. Thirty patients had previously undergone cataract surgery in their fellow eye under local anaesthesia. The anaesthetic technique used for 
these patients was topical anaesthesia (22), peribulbar anaesthesia (2), retrobulbar anaesthesia (1), and unknown (5).

Table 1 gives the preoperative visual acuity of the operated eye. Cataract morphology was nuclear sclerosis (30), cortical opacities (23), posterior subcapsular opacities (7), mixed opacities (37), and mature cataract (5). Some eyes had coexisting ocular pathology: glaucoma (5), age related macular degeneration (5), previous retinal detachment (2), corneal opacity (1), amblyopia (1), and background diabetic retinopathy (1). The location of the scleral tunnel incision was superior in 92 eyes and temporal in 10 eyes. Only one peroperative complication occurred comprising a small posterior capsule break without vitreous prolapse that did not preclude intraocular lens insertion into the capsular bag (anterior vitrectomy was not required).

The visual awareness of patients during surgery is summarised in Table 2. All patients found the operating microscope light very bright initially, but most rapidly became accustomed to it (within less than 1 minute). However, the operating microscope light did remain uncomfortably bright throughout surgery for two patients. The two light sources of the operating microscope were perceived as follows: two spots (83); a single spot (7); multiple spots (6); and a rectangle (3). Eight patients reported an appearance resembling reflections from a pair of spectacles. Colours were observed by 73 patients: blue (27); red/pink (15); orange (9); green (7); yellow/ gold (6); grey (2); and multicoloured (7). The remaining 29 patients were only aware of white illumination. Seven patients perceived flashes of light during surgery that were located in their peripheral visual field.

During the course of surgery, 49 patients observed a change in light brightness. The patterns described were gradual dimming followed by gradual brightening (24), gradual brightening (14), gradual dimming (10), and continual variations (1). Six patients lost light perception for a short interval during surgery. Four patients observed a sudden increase in

Table 1 Preoperative best corrected visual acuity of the operated eye

\begin{tabular}{ll}
\hline Visual acuity & $\begin{array}{l}\text { No of patients } \\
(n=102)\end{array}$ \\
\hline $6 / 6$ to $6 / 12$ & 52 \\
$6 / 18$ to $6 / 24$ & 35 \\
$6 / 36$ to $6 / 60$ & 5 \\
Counting fingers & 4 \\
Hand movements & 3 \\
Light perception & 3 \\
\hline
\end{tabular}

Table 2 Visual awareness of patients during surgery

\begin{tabular}{ll}
\hline Patient was aware of: & $\begin{array}{l}\text { No of patients } \\
(n=102)\end{array}$ \\
\hline Operating microscope light & 99 \\
Colours & 73 \\
Flashes of light & 7 \\
Vague movements & 19 \\
Surgical instruments or other objects & 12 \\
Change in light brightness during surgery & 49 \\
Change in colours during surgery & 30 \\
Transient visual alteration during corneal & \\
$\quad$ irrigation & 25 \\
\hline
\end{tabular}

brightness at the time of intraocular lens insertion. Thirty patients observed a change in colours during surgery, but there was no particular pattern. Corneal irrigation produced a transient visual alteration in 25 patients.

Additional visual perceptions were reported by four patients. Three patients reported that the operating microscope light vibrated constantly during surgery. One patient observed his retinal vessels as a black silhouette against an illuminated background on several occasions during surgery.

No patient found their visual experience during surgery unpleasant. There was no association between the various visual phenomena reported (Table 2) and the patients' age $(p>0.05, t$ test), sex ( $p>0.05$, Fisher's exact test), preoperative visual acuity $\left(p>0.05, \chi^{2}\right.$ test for trend), cataract morphology $\left(p>0.05, \chi^{2}\right.$ test), coexisting ocular pathology ( $p>0.05$, Fisher's exact test), or previous experience of cataract surgery under local anaesthesia ( $p>0.05$, Fisher's exact test).

\section{Discussion}

Only one previous study has systematically investigated the visual experience of patients during cataract surgery. ${ }^{12}$ This study assessed the visual experience of 56 patients during extracapsular cataract surgery under regional anaesthesia (peribulbar and retrobulbar blocks). Visual awareness was absent or limited to only light perception for four patients. The remaining patients observed colours (80\%), movements $(68 \%)$, flashes $(66 \%)$, abstract colour images (55\%), and objects (20\%). During the course of surgery, patients also observed a change in light brightness (64\%) and colours (20\%).

Limited aspects of the visual experience during extracapsular cataract surgery under regional anaesthesia have also been reported in two other studies. In one study, surgical instruments were observed by $73 \%$ of patients during surgery under retrobulbar anaesthesia. ${ }^{13}$ In another study, no patients observed surgical instruments during surgery under peribulbar anaesthesia but $20 \%$ of patients perceived abstract visual images. ${ }^{14}$ It has also been estimated that $10 \%$ of patients can clearly perceive surgical instruments during vitrectomy procedures under retrobulbar anaesthesia. ${ }^{15}$ The different findings of these studies are probably attributable to the variable efficacy of regional anaesthesia.

Regional anaesthesia generally produces a profound reduction in vision because of a direct effect of the anaesthetic agent on the optic nerve. ${ }^{16-19}$ The anaesthetic may also act indirectly through optic nerve compression if large volumes are injected into the orbit. Light perception is lost by approximately $20 \%$ of patients following peribulbar anaesthesia. ${ }^{14} 20$ There is, however, considerable variability in the degree of visual reduction that can occur with each method of regional anaesthesia (retrobulbar, peribulbar, and sub-Tenon's blocks). ${ }^{13} 142122$ Variations in both anaesthetic technique and diffusion of anaesthetic agents through the orbital tissues probably account for 
the varying degrees of optic nerve blockade observed.

In this study, no patient was found to have an unpleasant visual experience during phacoemulsification cataract surgery under topical anaesthesia. Comparison of specific aspects of the visual experience with the previous report ${ }^{12}$ is difficult because of differing techniques for cataract surgery, but the overall frequency of visual phenomena does not appear to be significantly greater for topical anaesthesia compared with regional anaesthesia. This is attributable to rapid bleaching of the retina by the operating microscope light which reduces visual awareness during surgery. The lower proportion of patients observing movements and flashes of light in this study may be due to less globe deformation during phacoemulsification cataract surgery compared with extracapsular cataract surgery. This study cannot, however, determine whether the intensity of the different visual phenomena observed by patients during surgery differs between topical and regional anaesthesia.

The operating microscope light was found to be uncomfortably bright throughout surgery by two patients. A previous comparative study has reported that discomfort from the operating microscope light is more common with topical than retrobulbar anaesthesia (though patients still only experienced mild discomfort). ${ }^{5}$ Discomfort from the operating microscope light may be avoided by starting with a low level of brightness which is then slowly increased during the initial stages of surgery. Regional anaesthesia may be required by the small minority of patients who cannot tolerate the operating microscope light despite this manoeuvre.

Topical anaesthesia for phacoemulsification cataract surgery has several advantages compared with regional anaesthesia. Firstly, it eliminates the risk of damage to the globe or orbital contents associated with retrobulbar and, less commonly, peribulbar injections. ${ }^{23-29}$ Secondly, it allows rapid visual rehabilitation following surgery with the potential for good vision in the immediate postoperative period. ${ }^{30} 31$ Thirdly, there is no postoperative ptosis or diplopia. ${ }^{30}$ Retention of full ocular motility may also be advantageous during surgery by improving surgical access. ${ }^{2457}$ Finally, topical anaesthesia can increase the time and cost efficiency of surgery because of reduced anaesthetic requirements. Perioperative sedation is not necessary for successful phacoemulsification cataract surgery under topical anaesthesia. ${ }^{24} 781011$

Preoperative patient counselling before phacoemulsification cataract surgery under topical anaesthesia should include information about the visual experience during surgery. The results of this study may be useful for preoperative counselling, though it is important to emphasise the variable nature of the visual experience. In particular, patients should be warned that they might temporarily lose vision during surgery so that this potentially frightening experience is ameliorated. A possible mechanism for this temporary loss of vision is transient elevation of intraocular pressure producing retinal ischaemia. ${ }^{32}$ Good preoperative counselling and constant surgeon-patient communication during surgery are essential for the successful application of topical anaesthesia.

Sources of funding: None

Propriety or financial interests: None

1 Nielsen PJ. A prospective evaluation of anxiety and pain with topical analgesia or retrobulbar anaesthesia for small (implant Refract Surg incision cata

2 Duguid IG, Claoue CM, Thamby-Rajah Y, et al. Topical anaesthesia for phacoemulsification surgery. Eye 1995;9: $456-9$

3 Zehetmayer M, Radax U, Skorpik C, et al. Topical versus peribulbar anesthesia in clear corneal cataract surgery. $\mathcal{F}$ Cataract Refract Surg 1996;22:480-4.

4 Manners TD, Burton RL. Randomised trial of topical versus sub-Tenon's local anaesthesia for small-incision cataract surgery. Eye 1996;10:367-70.

5 Patel BC, Burns TA, Crandall A, et al. A comparison of topical and retrobulbar anesthesia for cataract surgery. Ophthalmology 1996;103:1196-203.

6 Roman S, Auclin F, Ullern M. Topical versus peribulbar anesthesia in cataract surgery. $\mathcal{f}$ Cataract Refract Surg 1996; 22:1121-4.

7 Maclean H, Burton T, Murray A. Patient comfort during cataract surgery with modified topical and peribulbar ataract surgery with modified topical and peribur

8 Chittenden HB, Meacock WR, Govan JA. Topical anaesthesia with oxybuprocaine versus sub-Tenon's infiltration with $2 \%$ lignocaine for small incision cataract surgery. $\mathrm{Br} F \mathrm{Oph}$ thalmol 1997;81:288-90.

9 Shammas HJ, Milkie M, Yeo R. Topical and subconjunctival anesthesia for phacoemulsification: prospective study. $\mathcal{f}$ Cataract Refract Surg 1997;23:1577-80.

10 Johnston RL, Whitefield LA, Giralt J, et al. Topical versus peribulbar anesthesia, without sedation, for clear corneal phacoemulsification. $\mathcal{F}$ Cataract Refract Surg 1998;24:40710.

11 Nielsen PJ, Allerod CW. Evaluation of local anesthesia techniques for small incision cataract surgery. $\mathcal{F}$ Cataract Refract Surg 1998;24:1136-44.

12 Murdoch IE, Sze P. Visual experience during cataract surgery. Eye 1994;8:666-7.

13 Levin ML, O'Connor PS. Visual acuity after retrobulbar anesthesia. Ann Ophthalmol 1989;11:337-9.

14 Talks SJ, Chong NH, Gibson JM, et al. Visual acuity and pupillary reactions after peribulbar anaesthesia. $\mathrm{Br} f$ Ophthalmol 1994;78:41-3.

15 Mandelcorn MS, Mandelcorn E, Ananthanarayan C, et al. Some observations concerning visual perception during vitrectomy after retrobulbar anesthesia. Can $\mathcal{F}$ Ophthalmol 1997;32:255-6.

16 Doden W, Bopp M. Optikusblockade durch retrobulbäre Anästhesie. Klin Monatsbl Augenheilkd 1984;184:311-2.

17 Verma L, Arora R, Kumar A. Temporary conduction block of optic nerve after retrobulbar anesthesia. Ophthalmic Surg 1990;21:109-12.

18 Arora R, Verma L, Kumar A, et al. Peribulbar anesthesia and optic nerve conduction. F Cataract Refract Surg 1991;17: 506-8.

19 Ropo A, Ruusuvaara P, Setala K. Visual evoked potentials after retrobulbar or periocular anaesthesia. Brf Ophthalmol 1992;76:541-4

20 Scott RA, Acharya PA, Jakeman CM, et al. Peribulbar anaesthesia. Br f Ophthalmol 1994;78:592.

21 Brent BD, Singh H. The effect of retrobulbar anaesthesia on visual acuity in planned extracapsular cataract extraction. Ophthalmic Surg 1991;22:392-5.

22 Schimek F, Steuhl KP, Fahle M. Retrobulbar blockade of somatic, motor, and visual nerves by local anesthetics. Ophthalmic Surg 1993;24:171-80.

23 Nicoll JM, Acharya PA, Ahlen K, et al. Central nervous system complications after 6000 retrobulbar blocks. Anesth Analg 1987;66:1298-302.

24 Edge KR, Nicoll JM. Retrobulbar hemorrhage after 12,500 retrobulbar blocks. Anesth Analg 1993;76:1019-22.

25 Davis DB, Mandel MR. Efficacy and complication rate of 16,224 consecutive peribulbar blocks. A prospective multicenter study. F Cataract Refract Surg 1994;20:327-37.

26 Duker JS, Belmont JB, Benson WE, et al. Inadvertent globe perforation during retrobulbar and peribulbar anesthesia. perforation during retrobulbar and peribulbar anesthesia. outcome. Ophthalmology 1991;98:519-26.

27 Hay A, Flynn HW, Hoffman JI, et al. Needle penetration of the globe during retrobulbar and peribulbar injections. Ophthalmology 1991;98:1017-24.

28 Rainin EA, Carlson BM. Postoperative diplopia and ptosis. A clinical hypothesis based on the myotoxicity of local anesthetics. Arch Ophthalmol 1985;103:1337-9.

29 Esswein MB, von Noorden GK. Paresis of a vertical rectus muscle after cataract extraction. Am f Ophthalmol 1993; 116:424-30

30 Nielsen PJ. Immediate visual capability after cataract surgery: topical versus retrobulbar anesthesia. $\mathcal{f}$ Cataract Refract Surg 1995;21:302-4.

31 Brothers-Arbisser L, Wymore JG. Visual acuity immediately following phacoemulsification with subconjunctival anfollowing phacoemulsification with subconjunctia. Ophthalmic Surg Lasers 1996;27:640-2.

32 Steinert RF, Oster JG, Francis JM. Postoperative retinal ischemia with self-sealing cataract surgery incisions. Am $\mathcal{F}$ Ophthalmol 1997;123:124-5. 